\title{
AVALIAÇÃO DO TRATAMENTO DA ARTRITE SÉPTICA DO QUADRIL
}

\author{
TREATMENT EVALUATION OF SEPTIC ARTHRITIS OF THE HIP
}

Anastácio Kotzias Neto', Marco Aurélio Oliveira², Willian Nandi Stipp ${ }^{3}$

\section{RESUMO}

Objetivo: Revisão dos resultados do tratamento de 46 crianças, 47 quadris, com artrite séptica do quadril e a investigação da relação entre os fatores prognósticos e os resultados clínicos obtidos. Métodos: Foram classificados, do ponto de vista clínico e radiográfico, de acordo com as classificações de Hunka e a de Choi, e distribuídos em grupos para estudo estatístico. O grupo 1 foi formado por pacientes classificados como tipo IA, e o grupo 2 pelos pacientes tipos IB ao IVB. A doença acometeu 30 meninos, sendo o lado direito comprometido em 26 crianças e uma delas com acometimento bilateral. A média de idade na apresentação foi de 50 meses, sendo maior no grupo $1(\mathrm{p}=0,023)$. A cultura do líquido sinovial foi positiva em 23 pacientes e, dentre elas, em 18 cresceram Staphylococcus aureus. O tempo de sintomas até o tratamento cirúrgico teve média de 3,5 dias, sendo a espera no grupo 1 menor $(\mathrm{p}=0,03)$. Resultados: Quarenta e seis pacientes, 47 quadris, que compareceram ao Ambulatório da Ortopedia do HIJG, e responderam ao protocolo, submetidos a exame físico e radiografias da bacia, além da revisão de dados do prontuário. O resultado do tratamento foi satisfatório na grande maioria dos casos. Conclusão: Pacientes jovens, que, na apresentação, não claudicavam, com cultura do líquido sinovial positiva para Staphylococcus aureus e demora na instituição do tratamento cirúrgico constituíram fatores de pior prognóstico nos resultados.

Descritores - Artrite Séptica; Quadril; Crianças

\section{ABSTRACT}

Objective: Presenting a retrospective review of the results of treatment of children with septic arthritis of the hip and the investigation of the relationship between prognostic factors and the clinical results obtained. Methods: The patients evaluated (46) comprising 47 hips, who attended Orthopedics HIJG's ambulatory clinic, answered a questionnaire, underwent physical examinations and radiographs of the pelvis, as well as the review of data from medical records. The patients were classified in terms of clinical and radiographic point of view according to both the classifications of Hunka and Choi, and were divided into groups for statistical comparison. Group 1 consisted of patients classified as Type IA and group 2 consisted of patients classified as Type IB to Type IVB. Results: The disease affected 30 boys, affecting the right hip in 26 children and both sides in one child. The average age at the presentation was 50 months, being higher in group 1 ( $p=0.023)$. The synovial fluid culture was positive in 23 patients and Staphylococcus aureus grew in 18 of them. Symptoms lasted on average for 3.5 days before surgery, the wait being shorter in group $1(p=0.03)$. The treatment outcome was satisfactory in most cases. Conclusion: Young patients, who did not limp during the initial medical exam, with synovial fluid culture positive for Staphylococcus aureus and delay in undergoing surgical treatment, were associated with poor outcomes.

Keywords - Septic Arthritis; Hip; Childrens

\section{INTRODUÇÃO}

A artrite séptica (AS) foi descrita por Thomas Smith em 1874. É definida como uma infecção osteoarticular causada por microorganismo piogênico, excetuando-se o bacilo da tuberculose ${ }^{(1)}$, podendo apresentar mortalidade acima de $50 \%{ }^{(2,3)}$. De acordo com a literatura americana, a incidência de AS em crianças varia de, aproximadamente,
5,5 a 12 casos por 100.000 indivíduos $^{(1)}$, sendo o quadril a articulação mais acometida, seguida pelo joelho, ombro e cotovelo ${ }^{(1,3)}$. Pode ocorrer em pacientes de qualquer idade, sendo mais frequente em crianças na faixa etária compreendida até a metade da primeira década de vida ${ }^{(1,3)}$.

A artrite séptica do quadril difere da artrite em outras articulações periféricas pelo potencial de complicações

1 - Doutor em Medicina pela Unifesp-EPM; Chefe do Serviço de Ortopedia e Traumatologia do Hospital Infantil Joana de Gusmão de Florianópolis, SC, Brasil.

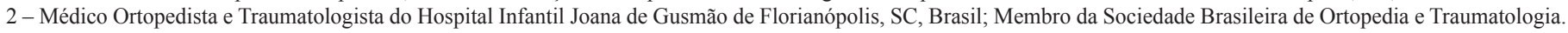

3 - Ex-Residente do Hospital Infantil Joana de Gusmão de Florianópolis, SC, Brasil; Membro da Sociedade Brasileira de Ortopedia e Traumatologia.

Trabalho realizado no Hospital Infantil Joana de Gusmão de Florianópolis, SC, Brasil.

Correspondência: Av. Jornalista Rubens de Arruda Ramos, 2.272/301 - 88015-702 - Florianópolis, SC. E-mail: akotzias@kotzias.com.br

Trabalho recebido para publicação: 24/08/2011, aceito para publicação: 31/08/2011.

Os autores declaram inexistência de conflito de interesses na realização deste trabalho / The authors declare that there was no conflict of interest in conducting this work 
que pode apresentar e consequente mau prognóstico ${ }^{(4)}$. Nesse contexto, deve-se lembrar da localização profunda da articulação do quadril, em que o médico assistente pode não evidenciar os sinais flogísticos clássicos de um processo infeccioso. Além disso, existem doenças com sintomas semelhantes, como a sinovite transitória do quadril, que podem confundir ou atrasar o seu diagnóstico ${ }^{(5)}$.

Diante de um paciente com suspeita de apresentar AS do quadril, o médico se depara com um desafio: o de diagnosticar uma enfermidade grave, incapacitante e devastadora $^{(5-8)}$ que deve ser considerada uma emergência ortopédica, necessitando de tratamento imediato. O possível atraso no diagnóstico e tratamento adequado e efetivo pode levar ao dano da cartilagem articular do acetábulo e fêmur proximal, da epífise, placa epifisária e metáfise femoral proximal, resultando em sequelas muito graves que irão comprometer o futuro da articulação envolvida ${ }^{(9,10)}$. Dentre elas, pode-se citar a perda da mobilidade articular, dor, claudicação, discrepância do comprimento dos membros e a artrose precoce ${ }^{(8-10)}$.

Os poucos dados registrando a incidência desta doença no nosso meio e sua relevância motivaram este estudo, que tem como proposta a revisão dos resultados do tratamento de crianças com AS do quadril e investigar a relação entre os fatores prognósticos e os resultados clínicos obtidos.

\section{MATERIAL E MÉTODOS}

Realizou-se um estudo tipo coorte, observacional, avaliando pacientes com diagnóstico clínico de AS do quadril submetidos a tratamento cirúrgico no Hospital Infantil Joana de Gusmão de Florianópolis (HIJG), no período compreendido entre janeiro de 1994 e junho de 2009.

No arquivo do serviço de ortopedia e traumatologia encontrou-se um total de 104 pacientes cadastrados. Procedeu-se busca ativa por contato telefônico para agendamento de consulta, resultando no comparecimento de 46 pacientes.

Foram incluídas neste estudo crianças com idade até os 14 anos e 11 meses, idade limite de atendimento aos pacientes no HIJG, com o diagnóstico de AS do quadril operadas e seguidas por um período mínimo de dois anos. Excluiu-se aqueles que receberam inicialmente tratamento cirúrgico em outro serviço, os que não compareceram à consulta e aqueles cujos prontuários estavam incompletos.

Os pacientes presentes relataram seu estado atual, submeteram-se a exame físico, realizaram radiografias da bacia e foram revisados os dados dos seus prontuários médicos arquivados no SAME. Os dados colhidos foram anotados no protocolo criado para essa pesquisa.

A classificação funcional de Hunka et $a l^{(10)} \mathrm{e}$ as classificações radiográficas de Choi et al ${ }^{(11)}$ e Forlin e Milani ${ }^{(12)}$ foram utilizadas para avaliar os pacientes assistidos. Criou-se dois grupos para comparação, sendo o grupo 1 formado por pacientes cuja classificação radiográfica corresponde ao estágio IA (quadril normal) de Choi et al $^{(11)}$ e o grupo 2 formado pelos pacientes que se enquadraram nos estágios de IB a IVB (Figura 1).

Os dados coletados foram armazenados em banco de dados criado no programa Windows Excel 2003, no qual foi realizada a comparação de médias. A análise estatística utilizou o teste de Fisher, o teste U de MannWitney e o teste $t$ não pareado. O nível de significância estabelecido foi de $5 \%(\mathrm{p}<0,05)$ (Figuras 2 e 3$)$.

O projeto proposto foi aprovado pelo Comitê de Ética em Pesquisa do Hospital Infantil Joana de Gusmão, e os pesquisadores declaram não haver nenhum tipo de conflito de interesse.

\section{RESULTADOS}

O estudo avaliou 47 quadris de 46 pacientes, sendo 30 meninos e 16 meninas; o lado direito foi acometido em 26 crianças e um caso bilateral. A idade no diagnóstico variou de 11 dias a sete anos e dois meses, com uma média de 50 meses (Quadro 1).

A apresentação clínica no diagnóstico mostrou dor articular em 46 (100\%), febre em 32 (69,5\%), limitação da amplitude de movimento e claudicação em 38 $(82,6 \%)$ e sinais flogísticos como rubor, edema e calor em quatro $(8,6 \%)$ dos casos (Tabela 1$)$.

A cultura do líquido sinovial mostrou-se positiva em $23(50 \%)$ dos casos, dentre eles 18 (39,1\%) eram Staphylococcus aureus. A hemocultura realizada em 24 casos teve resultado negativo em todos.

O tempo transcorrido desde o início dos sintomas até o tratamento cirúrgico teve uma média de 3,5 dias, variando de um a 15 dias. O tratamento instituído foi a artrotomia em 45 quadris, punção articular em dois, e, destes, um paciente foi submetido a reintervenção cirúrgica (Tabela 2).

No pós-operatório, 18 (39,1\%) pacientes foram imobilizados com tração, 10 (22\%) com tração seguida de gesso, seis $(13 \%)$ com gesso, quatro $(8,6 \%)$ com suspensório de Pavlik, dois (4,3\%) com tala e seis (13\%) sem imobilização (Tabela 3 ).

Segundo a classificação funcional de Hunka et $a l^{(10)}$, $44(95,6 \%)$ pacientes tiveram resultado satisfatório (45 articulações). Avaliando conforme a classificação radiográfica de Choi et al ${ }^{(11)}, 34(73,9 \%)$ pacientes (35 articulações) corresponderam ao estágio IA, seis (13\%) como IB, quatro $(8,6 \%)$ como IIA e dois $(4,3 \%)$ pacientes como IVA e, segundo os critérios de Forlin e Milani ${ }^{(12)}, 44$ (95,6\%) pacientes foram IA e dois (4,3\%) IIB (Figuras 4, 5 e 6 ). 


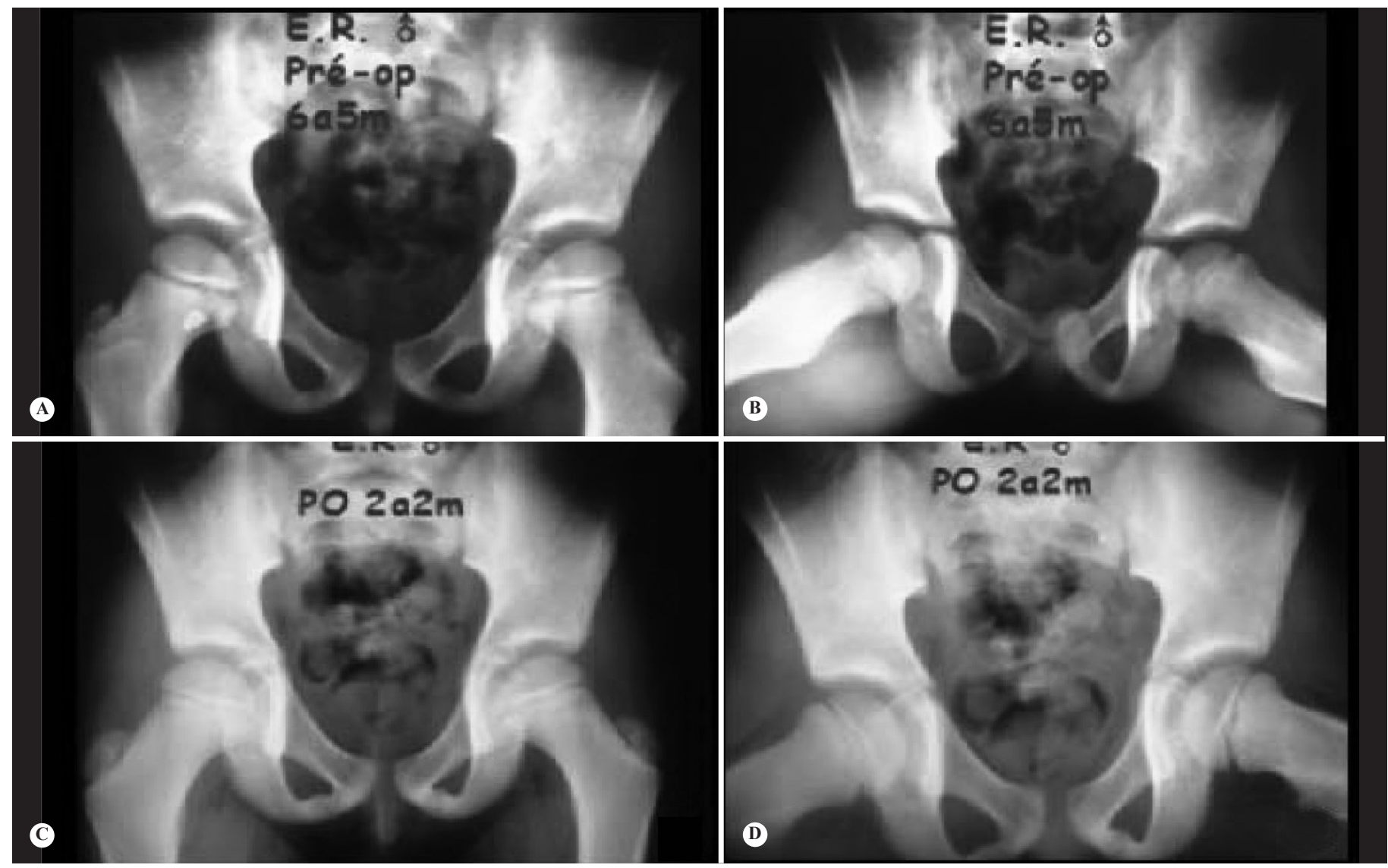

Figura 1 - Paciente masculino, 6a5m, radiografia de bacia panorâmica nas projeções em AP e Lauenstein, com história de febre, dor, claudicação e limitação funcional do quadril esquerdo há dois dias (A, B). Pós-operatório de $2 a 2 m$, paciente sem queixas e radiografia sem alteração.

Fonte: Choi et a/ ${ }^{(11)}$ e Forlin e Milani ${ }^{(12)}$.
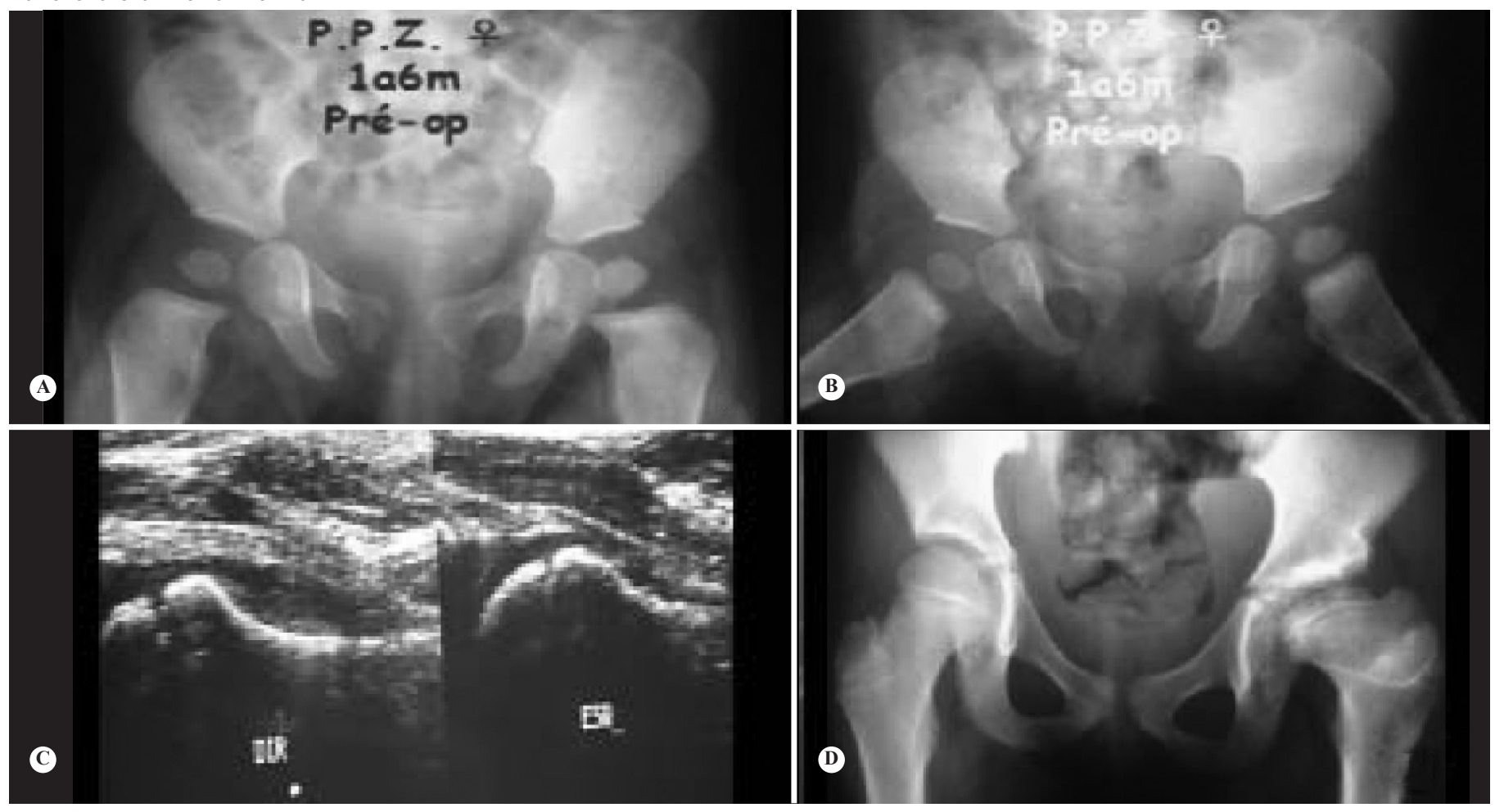

Figura 2 - Paciente feminino, 1a6m, radiografia de bacia panorâmica nas projeções em AP e Lauenstein, com história de dor, claudicação e limitação funcional do quadril esquerdo há quatro dias (A, B). Ultrassonografia mostrando distensão da cápsula articular (C). Pósoperatório de $8 \mathrm{a} 2 \mathrm{~m}$, paciente com claudicação e encurtamento de $1,5 \mathrm{~cm}$ sem queixas funcionais.

Fonte: Choi et a ${ }^{(11)}$ e Forlin e Milani ${ }^{(12)}$ 


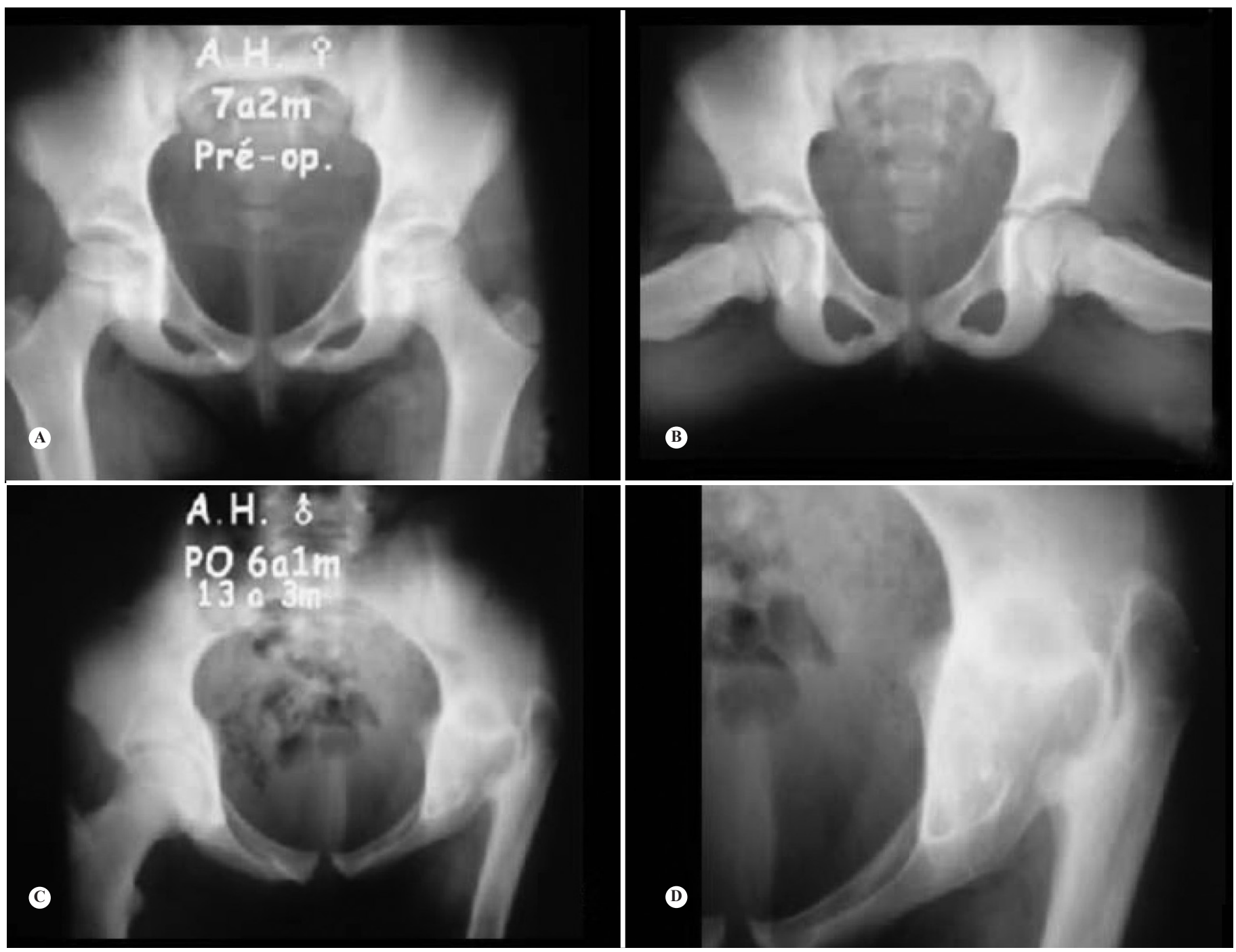

Figura 3 - Paciente, masculino, 7a2m, radiografia de bacia panorâmica nas projeções em AP e Lauenstein, com história de febre, dor, claudicação e limitação funcional do quadril esquerdo há cinco dias (A, B). Pós-operatório de 6a1m, paciente com 13a3m com claudicação e encurtamento de $4,5 \mathrm{~cm}$, dor e limitação funcional.

Fonte: Choi et $a^{(11)}$ e Forlin e Milani ${ }^{(12)}$

Quadro 1 - Dados dos pacientes relativos a gênero, idade no diagnóstico e lado acometido.

\begin{tabular}{|c|c|c|}
\hline Gênero & M 30 & F 16 \\
\hline Idade no diagnóstico & Mínima 11 dias & Máxima 7 anos e 2 meses \\
\hline Lado acometido & D 26 & E 21 \\
\hline
\end{tabular}

Tabela 1 - Dados relativos a apresentação clínica inicial.

\begin{tabular}{c|c|c}
\hline Queixas & no & $\%$ \\
\hline Dor & 46 & 100 \\
\hline Febre & 32 & 69,5 \\
\hline Limitação funcional & 38 & 82,6 \\
\hline Claudicação & 38 & 82,6 \\
\hline Sinais flogísticos & 4 & 8,6 \\
\hline
\end{tabular}

Tabela 2 - Tratamento instituído.

\begin{tabular}{c|c|c}
\hline Tipo & no & $\%$ \\
\hline Artrotomia & 45 & 95,7 \\
\hline Punção articular & 2 & 4,3 \\
\hline Total & 47 & 100 \\
\hline
\end{tabular}

Tabela 3 - Imobilização pós-operatória.

\begin{tabular}{c|c|c}
\hline Tipo & $\mathrm{n} \%$ & $\%$ \\
\hline Tração & 18 & 39,1 \\
\hline Tração + gesso & 10 & 22 \\
\hline Gesso & 6 & 13 \\
\hline Pavlik & 4 & 8,6 \\
\hline Tala & 2 & 4,3 \\
\hline Sem imobilização & 6 & 13 \\
\hline Total & 46 & 100
\end{tabular}




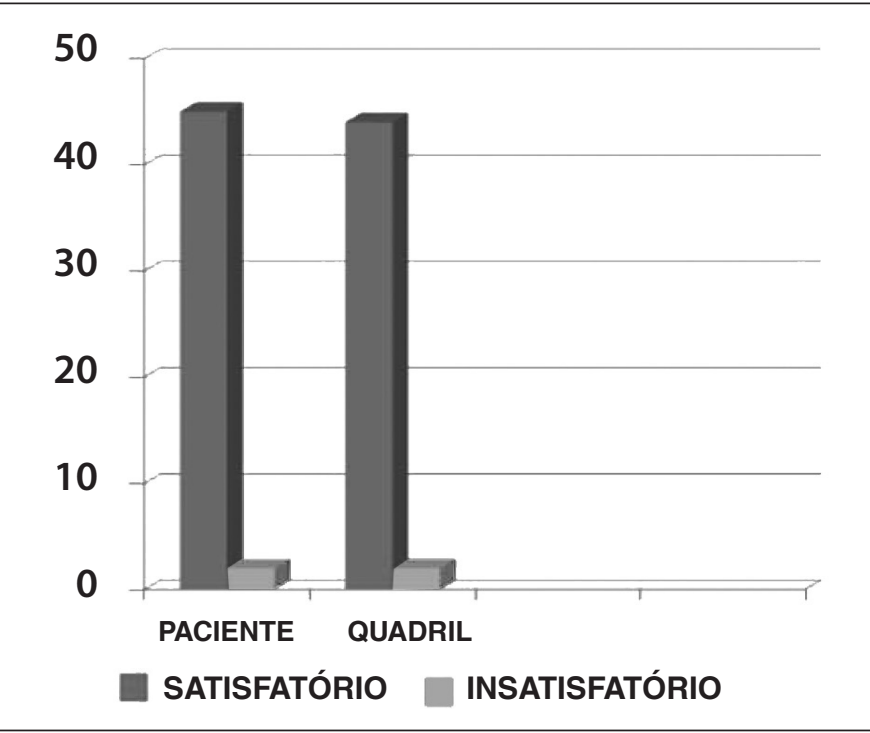

Figura 4 - Resultados segundo a classificação funcional de Hunka et $a{ }^{(10)}$.

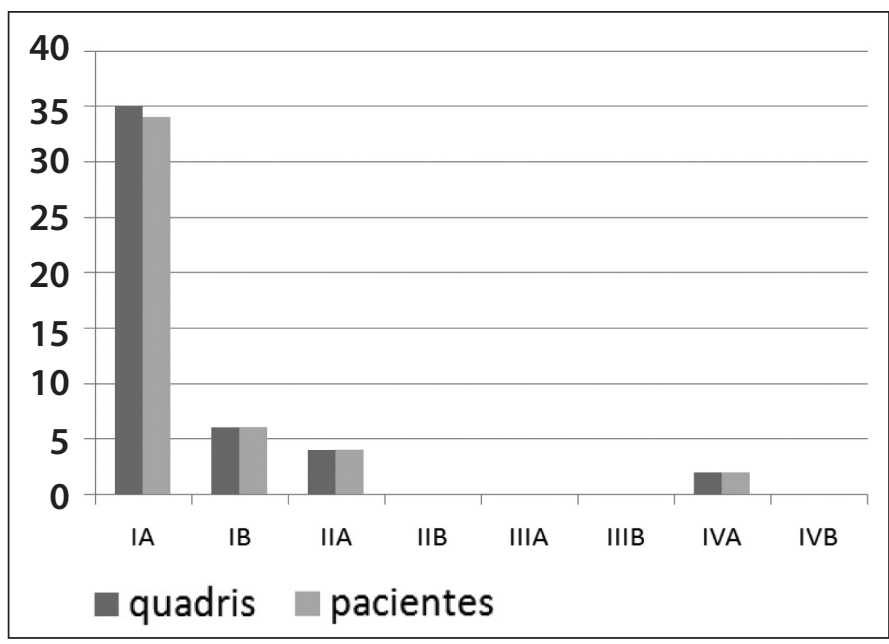

Figura 5 - Resultados segundo a classificação radiográfica de Choi et a(11).

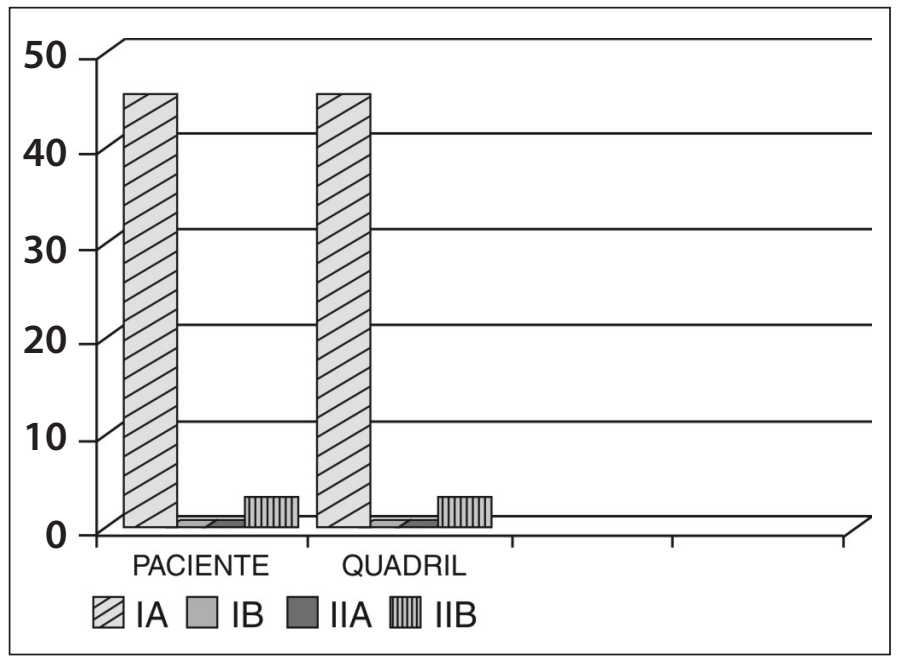

Figura 6 - Resultados segundo a classificação radiográfica de Forlin e Milani ${ }^{(10)}$.

\section{DISCUSSÃO}

O diagnóstico precoce da AS do quadril é fator decisivo para o sucesso do tratamento e obtenção de resultados satisfatórios, motivo do interesse e da investigação de muitos pesquisadores ${ }^{(5,6,12,13)}$. A maioria dos autores baseia sua decisão em sinais e sintomas clínicos, nos estudos de laboratório e de imagem ${ }^{(6)}$. Del Beccaro et $a l^{(14)}$ avaliaram 132 crianças e concluíram que a presença de derrame articular, febre maior que 37,5 graus e VHS maior que $20 \mathrm{~mm} / \mathrm{h}$ indicaria aspiração da articulação do quadril para afastar AS. Beach descreveu grupos de pacientes com alto e baixo risco de apresentarem a doença baseado na presença de irritabilidade, dor, febre maior que 38 graus e VHS maior que $20 \mathrm{~mm} / \mathrm{h}$, sendo que o grupo de alto risco deveria ser submetido à aspiração do quadril ${ }^{(15)}$. Eich et al ${ }^{(16)}$ desenvolveram seu algoritmo orientados pelo derrame articular do quadril e pelo menos dois dos seguintes critérios: temperatura retal maior que 38 graus, VHS maior que $20 \mathrm{~mm} / \mathrm{h}$ e PCR maior que $20 \mathrm{mg} / \mathrm{L}$. Kocher et al ${ }^{(17)}$ usaram quatro preditores para o diagnóstico diferencial de sinovite transitória e AS do quadril: história de febre, recusa em apoiar o membro inferior acometido, VHS maior que $40 \mathrm{~mm} / \mathrm{h}$ e contagem de leucócitos maior que $12.000 \mathrm{cels} / \mathrm{mm}^{3}$. Eles encontraram um valor preditivo para AS de $40 \%$ quando os pacientes apresentavam dois critérios, 93,1\% para três, e 99,6\% para quatro critérios concomitantes. Entretanto, no mesmo estudo, caracterizaram como artrite séptica verdadeira aqueles com crescimento bacteriano na cultura do líquido sinovial ou hemocultura e contagem de leucócitos maior que $50.000 / \mathrm{mm}^{3}$ no líquido sinovial. Diante disso, vê-se que a própria caracterização do diagnóstico é difícil. Os pacientes tratados no HIJG seguiram critérios semelhantes.

Lourenço et $a l^{(18)}$ consideram a maior incidência de anemia em crianças desnutridas, sugerindo que estas teriam maior propensão em desenvolver AS. Dos pacientes avaliados, $13(28,4 \%)$ tinham o valor da hemoglobina abaixo de $11 \%$ e 11 (23,9\%), valores abaixo de $10 \%$. Mesmo não mostrando diferença significante nos nossos pacientes, essa constatação parece corroborar seus relatos. Guarniero et $a l^{(19)}$ discordam, afirmando que a desnutrição não é fator para a gênese e evolução da AS. Embora haja divergências quanto à relação de desnutrição com AS, pelos resultados encontrados em nossos pacientes, salientamos a necessidade de averiguação de anemia concomitante nas crianças com AS possibilitando o devido tratamento.

O objetivo do tratamento cirúrgico é a drenagem da secreção purulenta e dos produtos da reação inflamatória 
para descomprimir a articulação, reduzir o inóculo bacteriano, retirar os detritos por meio da limpeza mecânica e impedir a ação proteolítica das enzimas, buscando proteger a articulação e facilitar a eficiência da terapêutica antibiótica $^{(7)}$. Assim, o procedimento mais aceito é a artrotomia ${ }^{(4-7,20)}$ seguida de irrigação e perfuração do colo, conduta terapêutica realizada nos pacientes deste estudo. A abordagem artroscópica se tornou opção valiosa ao oferecer benefícios como menor morbidade cirúrgica, menor tempo de internação e dor pós-operatória, recuperação mais rápida da mobilidade articular e melhor aparência estética ${ }^{(6,7,20)}$. Entretanto, segundo Givon et al ${ }^{(6)}$, a artrotomia e a drenagem via artroscópica necessitam de anestesia geral que pode ser dispensada quando se realiza a punção guiada por ultrassom ou intensificador de imagem. Essa técnica vem sendo bastante utilizada e com bons resultados, conforme estudos de Givon et $a l^{(6)}$ e Peltola et $a l^{(21)}$. Até o tratamento conservador é relatado em caso de diagnóstico muito precoce e boa resposta clínica aos antibióticos ${ }^{(1,2,5,7,21)}$. Chen et al ${ }^{(5)} \mathrm{ob}-$ servaram que alguns casos não responderam à drenagem por aspiração, e outros não necessitaram de artrotomia, concluindo que a escolha do método não é o fator mais importante, e sim a rapidez do diagnóstico e instituição do tratamento. No presente estudo, os pacientes tratados precocemente apresentaram os melhores resultados.

O tempo de duração da terapia intravenosa e oral ainda é assunto de discussão. Wilson e Paola ${ }^{(2)}$ referem que o tempo ideal de antibioticoterapia não é conhecido. Chen et $a l^{(5)}$ estabeleceram em seu trabalho duas semanas de terapia endovenosa e duas semanas via oral. Já Givon et $a l^{(6)}$ instituíram protocolo com três semanas EV e mais três semanas VO. Em estudo retrospectivo realizado por Kim et al avaliando 20 pacientes com AS de quadril, observa-se uma média de 8,2 dias de terapia parenteral, variando de três a 21 dias. O resultado funcional foi satisfatório em todos os casos, e na análise radiográfica nove pacientes apresentaram alterações, mas estavam assintomáticos ${ }^{(4)}$. Peltola et $a l^{(21)}$ conduziram estudo prospectivo, randomizado, comparando o resultado do tratamento de AS entre um grupo que usou antibiótico por 10 dias e outro grupo por 30 dias. Notaram uma recorrência no grupo de 30 dias - nos outros pacientes não houve recrudescência -, disfunção residual, alteração do crescimento ou sequela clinicamente significante, mostrando que o tratamento com a utilização de antibiótico por período curto teve bons resultados. O protocolo utilizado em nosso serviço nos últimos 10 anos preconiza um tempo médio de antibioticoterapia endovenosa de uma semana, convertida para via oral após melhora dos parâmetros clínicos e laboratoriais por mais três semanas.

Com relação aos resultados funcionais e radiográficos do tratamento dos pacientes com AS do quadril, a literatura tem descrito a associação com fatores de pior prognóstico. São citados a prematuridade, osteomielite do colo do fêmur, crianças que necessitam de terapia intensiva, retardo no início do tratamento, idade na época da infecção e tipo de bactéria $^{(5,6,8,10,11,13)}$. Dos critérios citados acima, nosso estudo encontrou correlação com a demora na instituição do tratamento, idade na apresentação da doença e com o tipo de bactéria.

Nesta avaliação, observou-se que o grupo 1, composto pelos pacientes classificados segundo os critérios de Choi et $a^{(11)}$ como tipo IA, apresentou média de idade de 62 meses comparado com uma média de 16 meses para o grupo 2, que foi composto pelos pacientes classificados como tipo IB ao IVB, demonstrando que os pacientes mais jovens apresentaram maior risco de pior resultado, à análise foi estatisticamente significativa $(p=0,023)$. Fato este que concorda com Galvão e Faria $^{(13)}$ em seu trabalho com 44 quadris com sequela de AS usando a mesma classificação, no qual apresentaram cinco casos do tipo I, 23 casos do tipo II, três casos do tipo III e 13 casos do tipo IV e notaram que as sequelas mais graves, tipos III e IV, ocorreram nos pacientes que tiveram artrite com menos de seis meses de idade. Da mesma forma, Choi et al $l^{(11)}$ descreveram cinco quadris tipo I, 11 tipo II, cinco tipo III e 13 tipo IV. Esse trabalho incluiu somente pacientes que tiveram a doença com idade menor que um ano. Concluíram que a deformidade foi maior nos menores de 12 semanas, principalmente nos neonatos. Além disso, prematuridade e osteomielite do colo foram associadas aos piores resultados.

Forlin e Milani ${ }^{(12)}$ também utilizaram as classificações de Choi et al ${ }^{(11)}$ e Hunka et al ${ }^{(10)}$ para seus 37 pacientes (41 quadris) com sequela de AS com início da doença até os três anos. Notaram que as sequelas mais graves foram nas crianças com início da doença no período neonatal, não encontrando diferença estatisticamente significante quando compararam por idade. Chen et $a l^{(5)}$, quando compararam entre menores e maiores de três anos, também não encontraram diferença. Estas constatações discordam dos nossos resultados, já que encontramos diferença com relação à idade.

Nos mais jovens, o suprimento sanguíneo é primordialmente intra-articular e, com o aumento da pressão intracapsular na artrite, ocorre prejuízos à vascularização da cabeça do fêmur ${ }^{(10)}$. Além disso, a maior quantidade 
de cartilagem na cabeça e colo torna essas estruturas mais suscetíveis, justificando o desfecho desfavorável nos pacientes mais jovens ${ }^{(4,13)}$.

Nos nossos pacientes, a média de tempo até a intervenção cirúrgica no grupo 1 foi de 2,3 dias, enquanto que no grupo 2 foi de 7,2 dias; essa diferença também foi estatisticamente significante e mostrando desfecho favorável nos pacientes operados precocemente $(\mathrm{p}=0,03)$. A rapidez na instituição do tratamento cirúrgico tem sido consenso entre os pesquisadores e corrobora os nossos resultados ${ }^{(1,5,9,11,20)}$, como demonstra o trabalho de Chen et al $l^{(5)}$, que avaliaram 33 pacientes graduando seus resultados em excelente, bom, moderado e ruim. A comparação entre grupos tratados com até cinco dias do início dos sinais e sintomas com aqueles com mais de cinco dias mostrou que, tanto no aspecto funcional quanto no radiográfico, houve diferença, mostrando os melhores resultados naqueles tratados de maneira precoce. Choi et al ${ }^{(11)}$ também observaram que o retardo maior que quatro dias no início do tratamento foi associado aos piores resultados. Estudos têm mostrado que a ação das enzimas proteolíticas e produtos de degradação dos leucócitos podem levar a danos irreversíveis na cartilagem articular e na placa de crescimento, a partir de 24 a 48 horas do início da doença ${ }^{(3,7,11)}$.

A claudicação na apresentação foi encontrada como fator de bom prognóstico quando da comparação entre os grupos $(p=0,04)$. Entende-se que aqueles que apresentam sintomatologia menos exuberante ao exame físico tiveram seu diagnóstico protelado, levando a demora na instituição do tratamento cirúrgico.

\section{REFERÊNCIAS}

1. Wang CL, Wang SM, Yang YJ, Tsai CH, Liu CC. Septic arthritis in children:relationship of causative pathogens, complications, and outcome. J Microbiol Immunol Infect. 2003;36(1):41-6.

2. Wilson NI, Di Paola M. Acute septic arthritis in infancy and childhood. 10 years' experience. J Bone Joint Surg Br. 1986;68(4):584-7.

3. Lourenço AF, Ishida A, Milani C, Filho JL, Kuwajima SS. Artrite séptica do quadril: diagnóstico e tratamento. Rev Diagn Tratam. 2002;7(3):30-5.

4. Kim HK, Alman B, Cole WG. A shortened course of parenteral antibiotic therapy in the management of acute septic arthritis of the hip. J Pediatr Orthop. 2000;20(1):44-7.

5. Chen CE, Ko JY, Li CC, Wang CJ. Acute septic arthritis of the hip in children. Arch Orthop Trauma Surg. 2001;121(9):521-6.

6. Givon U, Liberman B, Schindler A, Blankstein A, Ganel A. Treatment of septic arthritis of the hip joint by repeated ultrasound-guided aspirations. J Pediatr Orthop. 2004;24(3):266-70.

7. Matos MA, Guarniero R, Junior RMG. Artrite séptica do quadril. Rev Bras Orthop. 2006;41(6):187-94.

8. Dobbs MB, Sheridan JJ, Gordon JE, Corley CL, Szymanski DA, Schoenecker PL.Septic arthritis of the hip in infancy: long-term follow-up. J Pediatr Orthop.2003;23(2):162-8

9. Wada A, Fujii T, Takamura K, Yanagida H, Urano N, Surijamorn P. Operative reconstruction of the severe sequelae of infantile septic arthritis of the hip. $\mathrm{J}$ Pediatr Orthop. 2007;27(8):910-4.

10. Hunka L, Said SE, MacKenzie DA, Rogala EJ, Cruess RL. Classification and surgical management of the severe sequelae of septic hips in children. Clin Orthop Relat Res. 1982;(171):30-6.
Em nosso estudo, a positividade da cultura sinovial também foi um dado relevante e considerado de pior prognóstico, assim como a presença do Staphylococcus aureus nessa cultura positiva em comparação com outras bactérias, $p=0,045$ e $p=0,021$, respectivamente. Trabalhos como os de Wang et al ${ }^{(1)}$ e Wada et al ${ }^{(9)}$ mostram que o Staphylococcus aureus constitui fator de pior prognóstico; mas isso não é consenso, como mostra Chen et $a l^{(5)}$, que não encontraram diferença estatisticamente significante em seus pacientes. Nos nossos casos, notou-se forte associação da claudicação e dismetria no exame físico atual nos pacientes do grupo 2, considerados os de pior resultado $(p=0,01)$. Notamos também que a média de tempo no seguimento no grupo 2 foi maior que no grupo 1, observando que os piores resultados foram nos pacientes operados mais tarde.

Acreditamos que o melhor entendimento da doença, a disponibilidade dos métodos diagnósticos e a abordagem precoce proporcionam melhores resultados no tratamento da AS do quadril em benefício dos pacientes.

\section{CONCLUSÃO}

Pacientes mais jovens, com ausência de claudicação na apresentação, cultura do líquido sinovial positiva para Staphylococcus aureus e demora na instituição do tratamento cirúrgico constituíram fatores de pior prognóstico nos resultados.

11. Choi IH, Pizzutillo PD, Bowen JR, Dragann R, Malhis T. Sequelae and reconstruction after septic arthritis of the hip in infants. J Bone Joint Surg Am. 1990;72(8):1150-65.

12. Forlin E, Milani C. Sequelae of septic arthritis of the hip in children: a new classification and a review of 41 hips. J Pediatr Orthop. 2008;28(5):524-8.

13. Galvão S, Faria JP. Artrite séptica do quadril. Rev Bras Ortop. 1992;27(1):37-40.

14. Del Beccaro MA, Champoux AN, Bockers T, Mendelman PM. Septic arthritis versus transient synovitis of the hip: the value of screening laboratory tests. Ann Emerg Med. 1992;21(12):1418-22.

15. Beach R. Minimally invasive approach to management of irritable hip in children. Lancet. 2000;355(9211):1202-3.

16. Eich GF, Superti-Furga A, Umbricht FS, Willi UV. The painful hip: evaluation of criteria for clinical decision-making. Eur J Pediatr. 1999;158(11):923-8.

17. Kocher MS, Zurakowski D, Kasser JR. Differentiating between septic arthritis and transient synovitis of the hip in children: an evidence-based clinical prediction algorithm. J Bone Joint Surg Am. 1999;81(12):1662-70.

18. Lourenço AF, Pinto JA, Sodré H, Honmoto PK, Albertoni LJ, Batista F. Artrite séptica na criança. Acta Ortop Bras. 1999;7(3):113-20.

19. Guarniero R, Pedrinelli A, Gaumieri,MV. Avaliação do estado nutricional em 23 casos consecutivos de crianças com pioartrite e osteomielite. Rev Bras Ortop 1992;27(1-2):16-20.

20. Nusem I, Jabur MKA, Playford EG. Arthroscopic treatment os septic arthritis of the hip. Arthroscopy. 2006;22:902e1-902e3.

21. Peltola $H$, Pääkkönen $M$, Kallio $P$, Kallio $M J$; Osteomyelitis-Septic Arthritis (OMSA) Study Group. Prospective, randomized trial of 10 days versus 30 days of antimicrobial treatment, including a short-term course of parenteral therapy, for childhood septic arthritis. Clin Infect Dis. 2009;48(9):1201-10. 